\title{
Article \\ An Experiment on Cooperation in a CPR Game with a Disapproval Option
}

\author{
Koffi Serge William Yao
}

\begin{abstract}
CEE-M, CNRS, INRAE, 34960 Montpellier, France; yaok@excelia-group.com or willysergeyk@gmail.com
\end{abstract}
\begin{abstract}
This paper studies the standard version of the approval mechanism with two players in a common pool resource (CPR) extraction game. In the case of disapproval, the Nash extraction level is implemented. The paper investigates, experimentally, the extent to which the Nash threat leads to Pareto-improving extraction levels. Through our experiment, we confirm the effectiveness of the Nash threat in reducing CPR over-extraction. Although participants' behavior is mainly explained by rational thinking, inequity in payoff can also motivate their behavior. Moreover, we show that there is neither an order effect nor a framing effect. Finally, the reduction persists when the Nash threat is no longer in place.
\end{abstract}

Keywords: laboratory group behavior; common pool resource; approval mechanism

JEL Classification: C71; C72; C92; N5; D02

check for

updates

Citation: Yao, K.S.W. An Experiment on Cooperation in a CPR Game with a Disapproval Option. Games 2021, 12, 83. https://doi.org/10.3390/ g12040083

Academic Editors: Ulrich Berger and Yukihiko Funaki

Received: 25 June 2021

Accepted: 12 October 2021

Published: 26 October 2021

Publisher's Note: MDPI stays neutral with regard to jurisdictional claims in published maps and institutional affiliations.

Copyright: (C) 2021 by the author. Licensee MDPI, Basel, Switzerland. This article is an open access article distributed under the terms and conditions of the Creative Commons Attribution (CC BY) license (https:/ / creativecommons.org/licenses/by/ $4.0 /)$.

\section{Introduction}

People interact constantly with their peers in social life. Within these social interactions, many situations arise in which selfish, rational agents are unwilling to sacrifice their benefit to promote cooperation and achieve greater social benefits [1,2]. Thus, in the absence of explicit incentives, self-interest tends to dominate social interest and lead to inefficient outcomes, a situation called a social dilemma [3-6]. In the context of a common pool resource (CPR) game, the social dilemma leads to an over-extraction of the resource [7-15]. We experimentally investigate the extent to which the approval mechanism (AM hereafter) can mitigate over-extraction when the disapproval benchmark is the Nash equilibrium. Ref. [16] showed that the AM solves the social dilemma in the case of public good provision. Moreover, ref. [17] documented that the AM is also Pareto-improving in the case of a CPR game. The AM can be thought of as a way to promote cooperation between players by introducing an agreement on a collective sanction in case of disapproval. The underlying principle of the AM is therefore closely related to cooperative games. Indeed, ref. [18] has already shown that it is possible to transform a cooperative game into a non-cooperative game if the negotiation process in the cooperative game is treated as a stage in the noncooperative game in the way that each player uses all the essential strengths of their position. The AM operates in the same way.

The AM is a simple mechanism that can be used in simultaneous moves games, such as a voluntary contribution game or a CPR extraction game, in order to increase cooperation between players. In the CPR extraction game, each player chooses his/her level of extraction. When the AM is activated, the underlying game is transformed into a two-stage game. In stage 1, participants no longer make extraction decisions, but instead make extraction proposals. In stage 2, all proposals and their associated payoffs are made public, and each player must decide whether to approve or disapprove the proposals. If the group approves, the proposals are implemented. Otherwise, a uniform extraction (called disapproval benchmark or disapproval threat) is imposed on each one. In this paper, we consider the Nash equilibrium as the disapproval benchmark (hereafter called the Nash threat). The main reason for this is that the Nash equilibrium is the prediction of the CPR 
game. Therefore, it can be the easiest consensus disapproval benchmark and is the easiest to implement. Second, according to the evidence from laboratory experiments, the outcome of the CPR dilemma can be worse than the Nash equilibrium (see $[11,19,20])$. Since the Nash threat is fixed as an exogenous disapproval benchmark, the negotiation in the AM framework is based on the mutual (dis)approval of the proposals. Mutual (dis)approval defines whether the proposals or the Nash threat is implemented. This feature makes the AM a hybrid game, i.e., it is both cooperative in the sense of [18] and non-cooperative.

The introduction of the Nash threat in the CPR game changes the structure of the game by promoting individual and group extraction levels below the Nash extraction level [17]. Ref. [16] showed that the Nash threat increases contributions in the public good game, and [21] found that it induces cooperation in the prisoner's dilemma game. In this paper, we implement the Nash threat in a CPR extraction game. The CPR dilemma differs from the public good dilemma in two important ways: first, the payoff function is concave, and second, there is rivalry between players. We aim to investigate whether the Nash threat can lead to lower CPR extraction, i.e., higher cooperation, in this context.

This paper also addresses the persistent effect of the Nash threat. In real life, mechanisms can sometimes lead to a withdrawal [22], outright suppression, or reform. In fact, the change of administrator or regime may lead to a change in economic and social policies that may result in the withdrawal of the mechanism. This was the case when the United States left the Paris Agreement after the election of President Trump. Thus, to test the robustness of the Nash threat, we examine its persistent effect. We therefore explore several questions: Does the mechanism change players' behaviors? Does it continue to affect them even after it is removed? Are players familiar with the mechanism, or have they learned to cooperate, and can they continue to cooperate even if the mechanism is removed?

Unlike the existing literature, we test the robustness of the Nash threat in a two-player CPR game. First, we extend the dataset to confirm the effectiveness of the Nash threat observed in [17]. We examine in detail the reason that the Nash threat as the disapproval benchmark reduces CPR over-extraction to understand how subjects behave under the threat of Nash extraction. Third, we test the order effect, i.e., participants start with the CPR with the AM in sequence 1 and receive the AM in sequence 2 . Fourth, we test the persistent effect of the Nash threat. Finally, we examine the framing effect under the AM. Thus, through our experiment, we confirm the effectiveness of the Nash threat in decreasing the over-extraction of the CPR even with a larger number of observations with respect to [17]. Moreover, our results show that there is neither an ordering effect nor a framing effect. Finally, we show that the Nash threat is persistent.

The rest of the paper is organized as follows. Section 2 describes the experimental design, i.e., the CPR model and treatments. Section 3 deals with the results: a descriptive analysis and detailed results. Section 4 provides a discussion and concludes.

\section{Experimental Design}

\subsection{The Common Pool Resource (CPR) Game}

We consider the 2-player CPR game. The CPR model is very similar to those of $[17,20]$. Let us consider the CPR model in [20]. Ref. [20] assumes a player (or appropriator) who has an endowment noted $w$. Ref. [20] interprets the endowment (w) as the total time available to player $i$, and he/she divides this time between leisure and work. Work $\left(x_{i}\right)$ is the time that the player $i$ spends fishing in a joint fishery, i.e., in the common pool resource extraction.

In this work, we consider that each player has the same endowment, and $x_{i}$ is the part of $w$ that player $i$ allocates in the CPR (e.g., in the fishery). Thus, $x_{i}$ is the effort or investment of player $i$ in the CPR extraction. The CPR payoff function is given by the concave function $a X-b X^{2}$, where $X$ is the total effort of the group members in the CPR. The payoff of player $i$ from the CPR is proportional to his/her effort $\left(x_{i} / X\right)$. Therefore, the more player $i$ invests in the CPR, the higher his/her payoff level is. For this reason, 
his/her effort level can be interpreted as his/her extraction level. In the rest of the paper, the investment in the CPR will be referred to as extraction accordingly.

$w-x_{i}$ is the private investment of player $i$ (i.e., the real leisure time according to [20]). The CPR game consists of deciding which part of the endowment should be invested in the CPR (i.e., the level of extraction) and which part in a private activity. Obviously, when the player $i$ decides on the amount of his/her extraction from the CPR $\left(x_{i}\right)$, he/she also decides on his/her investment in his/her private activity. $\left(w-x_{i}\right)$.

The total payoff is given by:

$$
\pi_{i}\left(x_{i}, x_{j}\right)=\frac{x_{i}}{X}\left(a X-b X^{2}\right)+p\left(w-x_{i}\right)
$$

The symmetric Nash equilibrium is achieved by maximizing the profit of player $i$ and assuming that all players extract the same amount of CPR. Moreover, the optimal extraction is achieved by maximizing the sum of individual payoffs (see $[17,20])$. Using the same parameters ( $a=23, b=0.25$, and $p=5)$ as [11] and assuming that 1 token is equal to 3 units of endowment, we obtain Equation (2). Finally, since we are only dealing with groups of two players, the Nash equilibrium at the group level is 16 tokens (48 units) and the optimum is 12 tokens (36 units). At the individual level, the Nash equilibrium is 8 tokens ( 24 units) and the optimum is 6 tokens (18 units). Note that tokens are used for the experiment.

$$
\pi_{1}\left(x_{1}, x_{2}\right)=69 x_{1}-\frac{9}{4} x_{1}\left(x_{1}+x_{2}\right)+15\left(w-x_{1}\right)
$$

\subsection{Treatments}

We test the properties of the Nash threat (the Nash equilibrium as a disapproval benchmark) in the approval mechanism (AM) under the CPR. To do so, we considered three treatments (see Table 1). Each treatment consists of two sequences. In each sequence, the CPR game or CPR game with the AM is performed over ten periods. In Introduction treatment, participants play the CPR game in sequence 1 and the CPR game with the AM (hereafter the Nash threat) in sequence 2. In Withdrawal treatment, the reverse is true, i.e., participants play the CPR game with the Nash threat in sequence 1 and the Nash threat is withdrawn in sequence 2 as the CPR game is applied in sequence 2. Thus, the withdrawal treatment tests the ordering effect and the persistence effect of the Nash threat. Finally, we performed a control treatment. This allowed us to isolate or capture the effectiveness (i.e., the actual effect) of the Nash threat with respect to control.

Table 1. Summary of treatments.

\begin{tabular}{cccc}
\hline Treatments & Control & Introduction & Withdrawal \\
\hline Sequence $1(\mathrm{~S} 1)$ & $\mathrm{CPR}$ & $\mathrm{CPR}$ & $\mathrm{CPR}+$ Nash threat \\
\hline Sequence $2(\mathrm{~S} 2)$ & $\mathrm{CPR}$ & $\mathrm{CPR}+$ Nash threat & $\mathrm{CPR}$ \\
\hline Number of group & 17 & 30 & 19 \\
\hline $\begin{array}{l}\text { Note: CPR refers to the CPR game without any incentive. CPR + Nash threat refers to the CPR game with the } \\
\text { AM, i.e., the threat of Nash. }\end{array}$
\end{tabular}

In each period (see Appendix A), each player has an endowment of 10 tokens and decides on his/her CPR extraction level. The rest of his endowment is automatically invested in his/her private activity. The results for each participant in the same group (each extraction and the corresponding payoff) are displayed and become common knowledge. Thus, the next period can start. When the AM (i.e., CPR+Nash threat) is activated, the underlying game is transformed into a two-stage game. In stage 1, participants no longer make extraction decisions but instead make extraction proposals. In stage 2 , all proposals and their corresponding payoffs are made public, and each participant must decide whether to approve or disapprove the proposals. If the group mutually approves, 
the proposals are implemented. Otherwise, the predicted Nash extraction under unregulated CPR (CPR game) is imposed on everyone. The Nash extraction at the individual level is equal to 8 tokens and the corresponding payoff is 294. Sixty-six groups of two participants were involved in the experiment. Each participant took part in only one treatment. The experiment was programmed in zTree [23] and recruitment was conducted via ORSEE. All sessions were conducted in the Laboratory of Experimental Economics of Montpellier.

\section{Results}

This section deals with the summary statistics, the empirical strategy and detailed results.

\subsection{Summary Statistics}

Table 2 presents the average group extraction by sequence in each treatment. We observed that the group extractions under the CPR game (in control and in sequence 1 of Introduction treatments) are larger than under the CPR with the threat of Nash equilibrium (AM) or in sequence 2 (under CPR game) of the withdrawal treatment. Thus, the threat of Nash equilibrium decreases the over-extraction (see S2-S1 for Introduction treatments and the corresponding $p$-values of signed rank and K-S tests in Table 2). This reduction is persistent because there is no difference between sequence 1 and sequence 2 under the withdrawal treatments (see the $p$-values of signed rank and K-S tests in Table 2 for withdrawal treatments).

The detailed results supported by the outcomes of the regressions will be used to validate the properties of the Nash threat.

Table 2. Average group extraction by sequence.

\begin{tabular}{cccc}
\hline \multirow{2}{*}{ Treatments } & Control & Introduction & Withdrawal \\
\cline { 2 - 4 } & $\mathbf{( 1 )}$ & $\mathbf{( 2 )}$ & $\mathbf{( 3 )}$ \\
\hline sequence 1 (S1) & 15.74 & 15.35 & 14.34 \\
\hline sequence 2 (S2) & 16.23 & 14.07 & 14.81 \\
\hline S2-S1 & 0.49 & -1.28 & 0.47 \\
\hline$p$-value of signed-rank test & 0.168 & $0.012{ }^{* *}$ & 0.153 \\
\hline Note: ${ }^{* *}$ denotes significance at the 5-percent level and ${ }^{* * *}$ at the 1-percent level. & 0.418 \\
\hline
\end{tabular}

Basically, the two treatments with the Nash threat (introduction and withdrawal) were performed in two different frames (framing effect: see Figure 1). These frames are Aggregated payoff and Separated payoff (split payoff). In fact, each participant in the CPR game has two activities: the CPR extraction and the private activity. The total payoff is the sum of the payoffs of the two activities. In the experiment, the total payoff amount is communicated in the set of treatments labeled Aggregated payoff, while the payoffs from the two activities are reported separately in the set of treatments labeled Separated payoff. Therefore, participants in the treatments labeled Separated payoff make an extra effort by calculating the total payoff before making their decisions. Thus, the framing effect allowed us to examine the effect of participants' computational ability on the effectiveness of the Nash threat. The preliminary experiments showed that there is no framing effect (see Figure 1 and the $p$-values of the rank-sum tests are higher than 10\%). Therefore, we pooled the data to obtain two AM treatments (Introduction and Withdrawal).

\subsection{Detailed Results}

We ran Equation (3) for the support of Results 1 and 3.

$$
Y_{i t}=\alpha_{0}+\alpha_{1}[\text { sequence } \times A M]_{i t}+\alpha_{2}[\text { sequence }]_{t}+\alpha_{3}[\text { period }]_{t}+\beta_{i}+\sigma_{i t}
$$


where $Y$ is group extraction. $A M$ equals 1 for the groups that received the AM with the Nash treat (treatment named Introduction) and 0 for the control treatment. sequence equals 1 for sequence 2 of the introduction treatment and sequence 2 of the control treatment, and 0 for sequence 1 of the introduction and the control treatments. sequence $\times A M$ is the interaction variable, i.e., our variable of interest that captures the effect of the Nash threat in the DiD approach. $\beta_{i}$ is the group fixed effect. $\sigma_{i t}$ is the term of the error. The regression is reported in column 1 of Table 3.

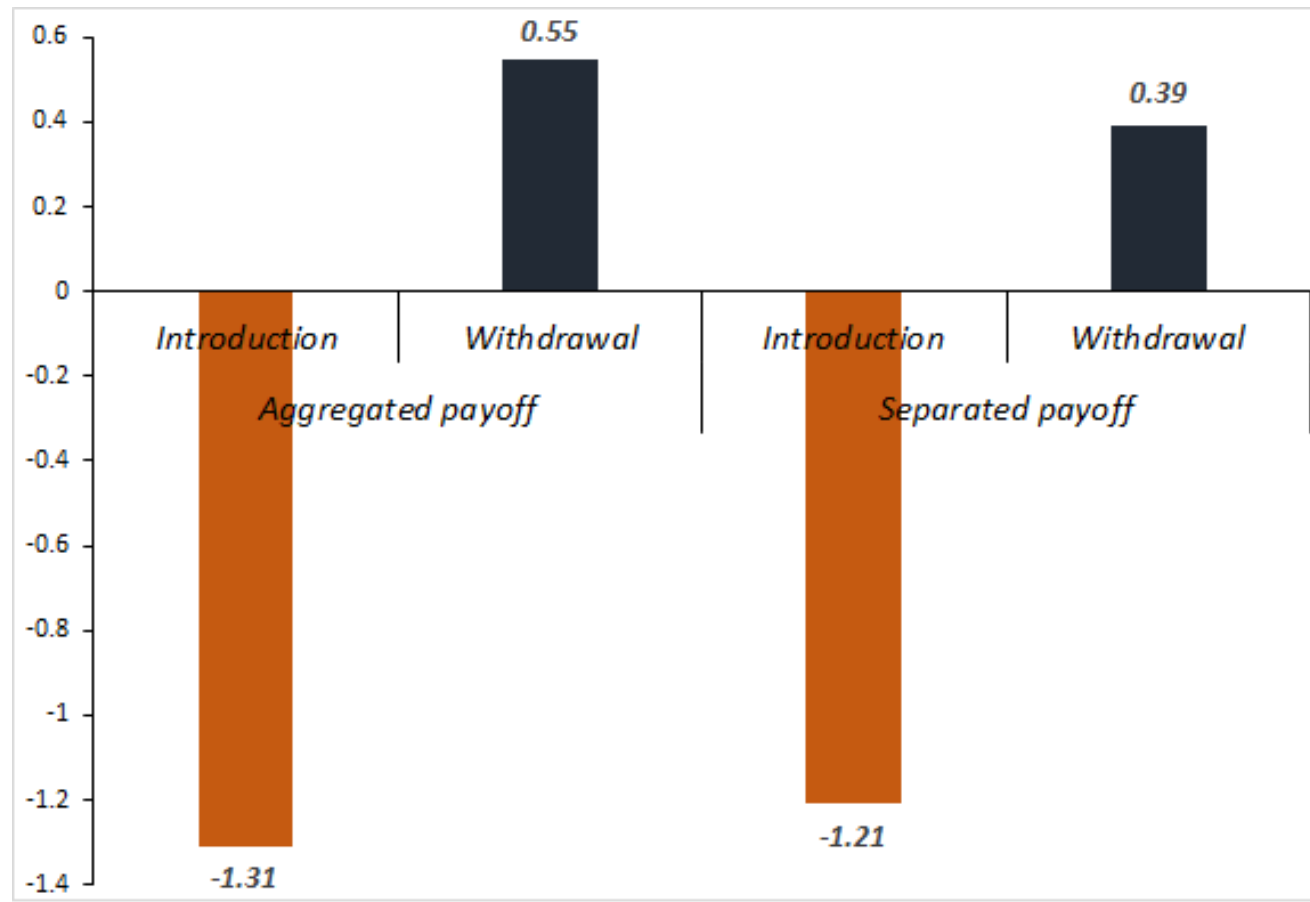

Figure 1. Framing effect: difference of group average extraction between sequences 2 and 1.

Table 3. Main regressions.

\begin{tabular}{|c|c|c|c|}
\hline & \multicolumn{2}{|c|}{ Introduction } & \multirow{2}{*}{$\begin{array}{c}\text { Withdrawal } \\
\text { (3) }\end{array}$} \\
\hline & (1) & (2) & \\
\hline sequence $\times A M$ & $\begin{array}{c}-1.77^{* * *} \\
(0.307)\end{array}$ & & $\begin{array}{c}-0.02 \\
(0.307)\end{array}$ \\
\hline Mutual approval & & $\begin{array}{c}-3.06 \text { *** } \\
(0.281)\end{array}$ & \\
\hline sequence & $\begin{array}{c}-0.14 \\
(0.355)\end{array}$ & & $\begin{array}{c}0.17 \\
(0.347)\end{array}$ \\
\hline period & $\begin{array}{c}0.06 \\
(0.025)\end{array}$ & $\begin{array}{c}-0.01 \\
(0.019)\end{array}$ & $\begin{array}{c}0.03 \\
0.026\end{array}$ \\
\hline constant & $\begin{array}{c}15.14^{* * *} \\
(0.175)\end{array}$ & $\begin{array}{c}16.08 * * * \\
(0.346)\end{array}$ & $\begin{array}{c}14.82 \text { *** } \\
(0.182)\end{array}$ \\
\hline $\begin{array}{c}\text { GroupFE } \\
\text { Prob }>F \\
\text { Observation }\end{array}$ & $\begin{array}{c}\text { yes } \\
0.000 \\
940\end{array}$ & $\begin{array}{c}\text { yes } \\
0.000 \\
300\end{array}$ & $\begin{array}{c}\text { yes } \\
0.011 \\
720\end{array}$ \\
\hline
\end{tabular}

Note: Robust standard errors are in parentheses. ${ }^{* * *}$ denotes significance at the 10 -percent level. The regressions contain period, sequence and group fixed effect. The variable sequence equals 1 for sequence 2 and 0 for sequence 1. In column (1), the variable $A M$ equals 1 for the Introduction groups and 0 for the control groups. In the same way, in column (3), the variable $A M$ equals 1 for the Withdrawal groups, and 0 for the control groups The variable sequence $\times A M$ captures the effect of the AM (the threat of Nash). In column (2), the variables $A M$, sequence and sequence $\times A M$ are the same and equal 1 since approval stage appears in sequence 2 of introduction treatment. The variable Mutual approval equals 1 if the two players mutually approve and 0 if at least one player disapproves. Group FE stands for "group fixed effect". 


\subsubsection{Cooperation under the Nash Threat}

Our first finding is reported in Result 1.

Result 1: The Nash threat reduces the over-extraction of the CPR and, therefore, increases cooperation among participants.

Support for Result 1: In order to support Result 1, we use the difference-in-differences (DiD) estimation method. The DiD procedure is used to measure the effectiveness of the treatment by comparing the difference between the control groups and the groups subjected to the Nash threat (the AM) before and after the introduction of the Nash threat. It allows us to control for group and temporal characteristics by isolating the real impact of the Nash threat in reducing the group over-extraction observed in the control groups. The first differences concern the differences in group extraction between sequence 2 and sequence 1 (S2-S1) of the Control and Introduction treatments (see columns (1) and (2) of Table 2). These values are 0.49 and -1.28 for the Control and Introduction, respectively. The second difference refers to the difference between S2-S1 of the treatments named Introduction and Control, i.e., $-1.28-0.49=-1.77$. The coefficient of interest in the DiD is highly significant, indicating that the Nash threat significantly reduces the over-extraction of the $\mathrm{CPR}$, which is materialized by increasing the cooperation between subjects.

The support for Result 1 is reached by running Equation (3).

\subsubsection{The Driver of the Approval decision}

We examine in detail the reason that the Nash extraction as the disapproval benchmark reduces CPR over-extraction. In fact, the approval stage is added in stage 2 under the AM. If the subjects mutually approve, the proposed group extraction is implemented. However, if only one subject approves or in case of mutual disapproval, the Nash threat is implemented. Before deciding to approve or disapprove, each group member has three pieces of information: his extraction and payoff, his/her partner's extraction and payoff, and the extraction and payoff of the disapproval benchmark, i.e., the Nash threat. The rational player compares his/her payoff to the payoff of the Nash threat, and the other consideration is to compare his/her payoff to that of his/her partner. According to our CPR model and the parameters used, the symmetric Nash equilibrium is eight tokens and the resulting payoff is 294 for each player in a group with two members. Thus, under the AM with the Nash threat, the selfish rational player approves only if his/her payoff from the proposals is greater than or equal to 294, and disapproves only if his/her payoff is lower than 294. We define this type of approval and disapproval decision as rational approval and rational disapproval, respectively. The other cases of approval/disapproval correspond to the other consideration. Consequently, we distinguish between rational (dis)approval and (dis)approval based on other considerations (see Figure 2).

We observed $60 \%$ of mutual approval and $40 \%$ (nobody approved and only one approved) of disapproval. For the $40 \%$ of disapproval, only $5 \%$ are mutual disapproval, and the rest, i.e., 35\%, corresponds to one subject's approval (see Figure 3). Moreover, overall, the average proposed group extraction with mutual approval is lower than the average proposed group extraction with disapproval. Therefore, mutual approval seems to drive the reduction in over-extraction due to the Nash threat. To confirm this effect, we add the variable Mutual approval to Equation (3) to account for group approval. This variable is coded as 1 if both participants in the group mutually approve of the proposed extractions and 0 if otherwise. Note that the variable "Mutual approval" is exactly the same as the variable sequence $\times A M \times[$ Mutual approval $]$. The regression is reported in column 2 of Table 3 . This regression confirms that the reduction in group over-extraction is driven by the mutual approval of the proposals, since the coefficient of the variable Mutual approval $(-3.06)$ is significant. In fact, our analysis shows that subjects who approve are those who extract more from the resource, cooperate less, and have higher earnings. Thus, mutual approval implies that both subjects make a cooperative effort, which increases the payoff of both and minimizes the difference in payoff between the two subjects. 


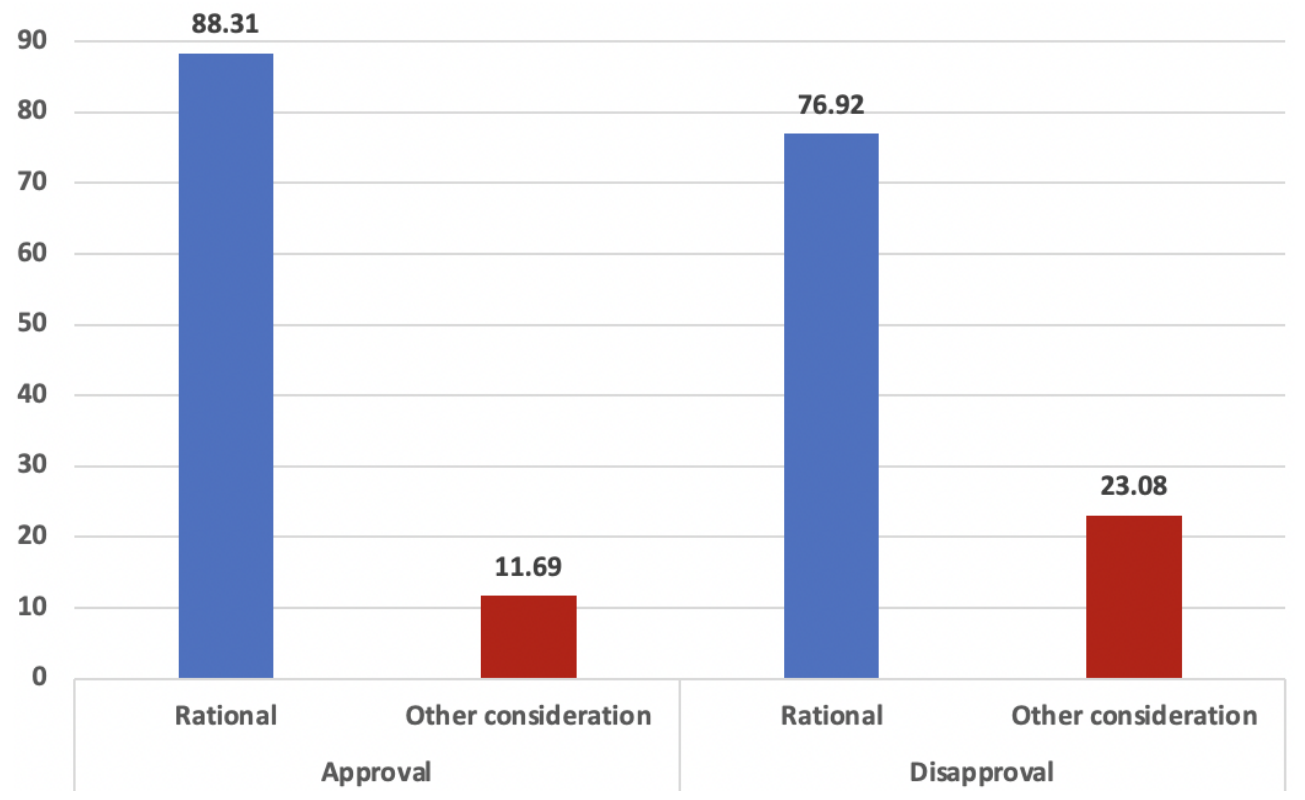

Figure 2. Individual (dis)approval rate (\%).

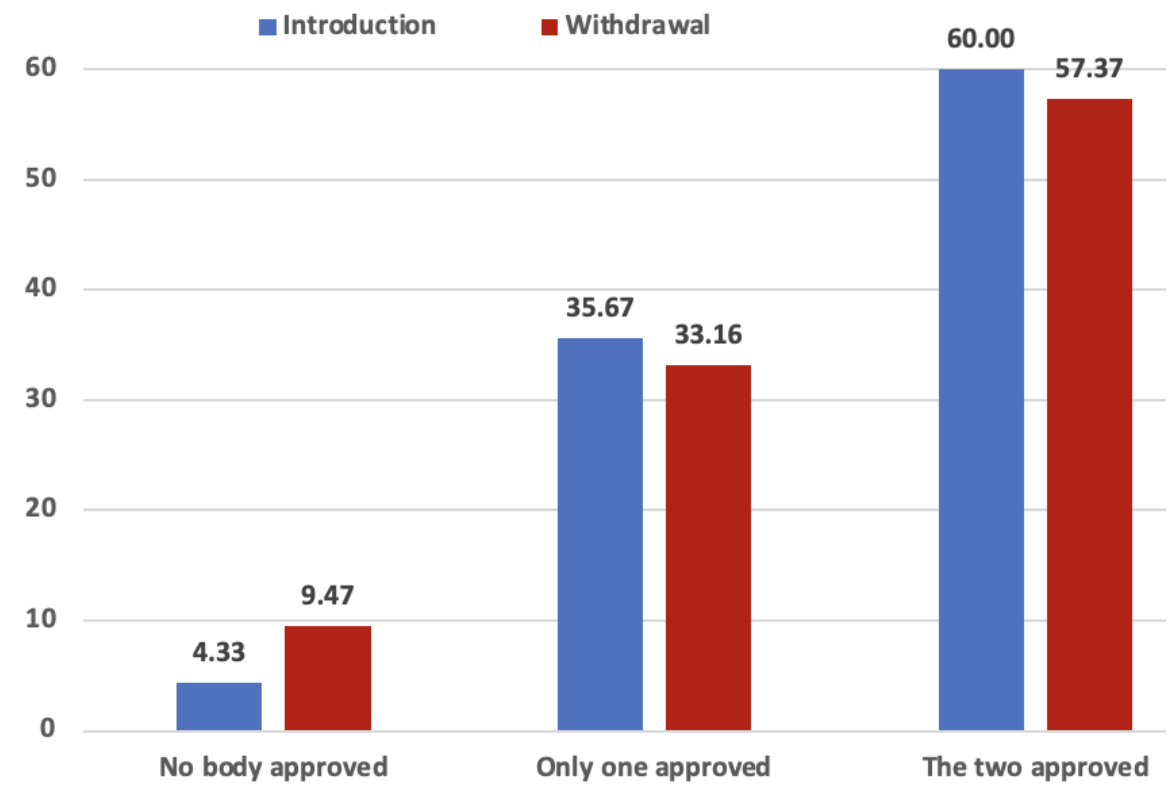

Figure 3. Group (dis)approval rate (\%).

At the individual level, we observed $82.67 \%$ of approval decisions and $17.33 \%$ of disapproval decisions. Moreover, $88.31 \%$ of approval decisions are rational, while $76.92 \%$ of disapproval decisions are rational. Thus, $11.69 \%$ of approval decisions and $23.08 \%$ of disapproval decisions are made with other considerations (see Figure 2). Therefore, we examine whether rationality and other considerations influence the decision to approve or disapprove. To do so, we determine the marginal effect of the following probit model:

$$
\operatorname{prob}\{\text { approval }\}=\operatorname{prob}\left\{\gamma_{0}+\gamma_{1} \text { rational }+\gamma_{2} \text { inequity }+\epsilon\right\}
$$

where the variable approval is equal to 1 if the subject approves and 0 if he/she disapproves. The variable rational is coded as 1 if the participant's payoff is greater than or equal to 294 , and 0 if his / her payoff is less than 294. The variable inequity, which represents the other consideration, is coded as 1 if the participant receives a lower payoff than his/her partner, and 0 if he/she receives a greater or equal payoff compared to his/her partner. 
We ran the probit model regression on the approval/disapproval decisions in sequence 2 of treatment introduction. The marginal effects are $46.22 \%$ and $-13 \%$ for the rational and inequity variables, respectively. The coefficients of the two variables are statistically significant at $1 \%$. Thus, the probability that a participant approves the proposed extractions increases by $46.22 \%$ when his/her payoff is greater than the Nash payoff and decreases by $13 \%$ when his/her payoff is lower than his/her partner's payoff. We can conclude that although (dis)approval is mainly explained by rational thinking, there are also some situations in which inequity motivated participant's behavior.

\subsubsection{The Order Effect of the Nash Threat}

Our second finding is reported in Result 2.

Result 2: Whatever the Nash threat is implemented in sequence 1 or in sequence 2, the group extraction is reduced, and therefore the cooperation increases among group members.

Support for Result 2: We performed the rank-sum test for the average group extractions by period in sequence 1 of the control treatment (CPR game) compared to those in sequence 1 of the withdrawal treatment (CPR game with AM). This rank-sum test ( $p$-value $=0.000)$ shows that the average group extraction under the withdrawal treatment is lower than the average group extraction under the control treatment. Since there is no difference between sequences 1 and 2 under the control treatment (see the $p$-value of the signed-rank test in column 1 of Table 2), we also performed the rank-sum test for the average group extractions by period in sequence 2 of the control treatment (CPR game) versus those in sequence 2 of the introduction treatment (CPR game with AM). This second rank-sum test $(p$-value $=0.000)$ also shows that the average group extraction under the introduction treatment is lower than the average group extraction under the control treatment. According to the results of the above rank-sum tests and with respect to Result 1 , we can conclude that regardless of whether the Nash threat is implemented in sequence 1 or in sequence 2, group extraction is reduced, and therefore the cooperation increases.

\subsubsection{Persistent Effect of the Nash Threat}

Our third finding is reported in Result 3.

Result 3: The Nash threat has a persistent effect on the reduction in the over-extraction of the CPR.

Support for Result 3: First, we conducted the rank-sum test with sequence 2 of the control treatment (CPR game) and sequence 2 of the withdrawal treatment (CPR game), because there is no difference between sequences 1 and 2 under the control treatment and under the withdrawal treatment, respectively (see $p$-values of the signed-rank test in columns 1 and 3 of Table 2). The rank-sum shows that the average group extraction is lower under sequence 2 of the withdrawal treatment than under sequence 2 of the control treatment. Second, we performed Equation (3), where sequence is coded as 1 for sequence 2 of the withdrawal treatment and sequence 2 of the control treatment, and 0 for sequence 1 of the withdrawal treatment and sequence 1 of the control treatment. period represents the periods under withdrawal and control treatments. $A M$ is coded as 1 for the withdrawal treatment and 0 for the control treatment. The variable sequence $\times A M$ is our variable of interest, capturing the effect of withdrawal of the Nash threat. The regression is reported in column 3 of Table 3. This coefficient is not significant (see column 3 of Table 3). Thus, withdrawing the Nash threat in sequence 2 does not significantly alter the average group extraction and cooperation level. For both reasons, we can conclude that the Nash threat has a persistent effect with regard to reducing CPR over-extraction.

\section{Discussion and Conclusions}

In this paper, we study the two main properties of the Nash threat in a two-player common-pool resource dilemma through an experiment with three treatments (see Table 1). The two main properties are based on the increase in cooperation between participants and the persistent effect when the Nash threat is removed. We found that the Nash 
threat significantly reduces the over-extraction of the resource. Moreover, the reduction is persistent when the Nash threat is no longer present. Our results also show that there is neither an ordering effect nor a framing effect.

The introduction of the Nash threat changes the structure of the basic CPR game. This structural change could therefore explain the reduction in CPR over-extraction and hence the increase in cooperation level. Indeed, under the AM, each participant compares his/her payoff from the stage 1 proposals to the payoff from the Nash equilibrium. If his payoff is greater than or equal to the payoff from the Nash equilibrium, he approves; otherwise, he disapproves. In theory, ref. [17] show that the set of extractions that survive to the elimination of the weakly dominated strategies are lower than the extraction level of the Nash equilibrium. This prediction is mostly observed in our experiment when the Nash threat is applied. However, other consideration (inequity), i.e., the difference between the payoff of the considered subject and his/her partner, explain part of the participants' behavior.

Our results suggest that the Nash threat is credible because it increases cooperation, even if it is no longer present. On the other hand, it does not allow us to implement the optimum. Note that [21] compared the Nash threat in the Prisoner's Dilemma with the mechanism of [24] and showed that the Nash threat performs better than the mechanism of [24]. It will also be interesting to do so in the case of CPR. We can compare it with the mechanism of [25]. It will be worth considering an alternative withdrawal test by adding a third sequence to the experiment, e.g., CPR game in sequence 1, CPR game with AM (the Nash threat) in sequence 2, and CPR game in sequence 3 . We can increase the group size and apply the AM in "give and take" [26], which might help us to compare the AM in CPR and the AM in public goods provision.

Funding: This research received no external funding.

Institutional Review Board Statement: Ethical review and approval were waived for this study, due to the absence of personal data.

Informed Consent Statement: Informed consent is mandatory for all participants that are registered in the LEEM subject pool. Detailed information can be found on the LEEM website (see http: //leem.umontpellier.fr/orsee3/public/rules.php and http://leem.umontpellier.fr/orsee3/public/ privacy.php).

Data Availability Statement: The data presented in this study are available on request from the corresponding author.

Acknowledgments: I thank Marc Willinger and Emmanuelle Lavaine for their proofreading and suggestions, and my colleague Imane for her proofreading. Special thanks to the two referees whose comments served to improve the quality of this work, the Academic Editors, and the Assistant Editor that followed each step for his patience.

Conflicts of Interest: The author declares no conflict of interest.

\section{Appendix A. Instructions}

Appendix A.1. Welcome

We thank you for agreeing to participate in this decision-making experiment. This experiment will be paid. Your earnings will depend on your decisions as well as those of the other participants in this experiment. Your identity and decisions will be kept anonymous. You will have to indicate your choices on the computer in front of which you are seated, and the computer will notify your earnings (in points) as the experiment progresses.

From now until the end of the experiment we ask you to stop all communication. If you have any questions, please raise your hand, an instructor will answer you privately. 


\section{Appendix A.2. General Procedure}

At the beginning of the experiment you will be randomly assigned to a group of two players. The composition of your group remains unchanged until the end of the experiment. Each member of your group (including you) will have an ID 1 or 2.

The experiment is divided into 2 parts. Each part consists of a series of ten periods. The rest of the instructions concern only part 1 . At the end of part 1 , you will receive new specific instructions for part 2. At the end of the experiment, one of the 20 periods will be drawn and your earnings (in points) for that period will be converted into euros according to a rule defined at the end of the instructions.

Once all participants have read the instructions, an experimenter will read them out loud again. After reading the instructions, you will be asked to complete a questionnaire to verify your understanding of the experiment. When all participants have completed this questionnaire, the experiment will begin.

\section{Appendix A.3. Types of Investments}

In each period, each player of your group has 10 tokens, which he has to split between two activities: activity A and activity B. activity A is common to both players. Activity B is specific to each player. Each token must be invested, either in activity A or in activity B. Earnings associated with your investment in each activity and the total earnings are described as follows.

Appendix A.3.1. Earnings Activity A

Your earnings from activity A depend on your investment in activity A and the investment in the activity A of the other player in your group.

This part is only for the set of treatments of Separated Payoff: We present the different possibilities of earnings in activity A. They are described in the earnings Table (see Table A1). The first column corresponds to your investment in activity A (between 0 and 10). The other columns correspond to the other player's investment in activity A (between 0 and 10). Your earnings in activity A and the other player's earnings $\mathrm{n}$ activity A are measured in points. There are two values in each cell of the Table: Your total earnings in points (in blue) and the other player's total earnings in points (in black). For example, you decide to invest 8 tokens in activity $\mathrm{A}$ and therefore 2 tokens in your activity $\mathrm{B}$. The other player decides to invest 6 tokens in activity A and therefore 4 tokens in his activity B. Your earnings in activity A for the period is 300 points. The total earnings of the other player of your group are 225 points.

Appendix A.3.2. Earnings from the Investment in Activity B

Your earnings from activity B depend solely on your own investment in that activity. Each token invested in activity B earns you 15 points. Similarly, each token that the other player invests in his activity B earns him 15 points.

\section{Appendix A.3.3. Total Earnings}

Your total earnings in each period are equal to your earnings from activity $\mathrm{A}+$ your earnings from activity $B$.

This part is only for the set of treatments of Aggregated Payoff: We present the different possibilities of total earnings. They are described in the earnings Table (see Table A2). The first column corresponds to your investment in activity A (between 0 and 10). The other columns correspond to the other player's investment in activity A (between 0 and 10). Your total earnings and the other player's earnings are measured in points. There are two values in each cell of the Table: Your total earnings in points (in blue) and the other player's total earnings in points (in black). For example, you decide to invest 8 tokens in activity $\mathrm{A}$ and therefore 2 tokens in your activity B. The other player decides to invest 
6 tokens in activity A and therefore 4 tokens in his activity B. Your total earnings for the period are 330 points. The total earnings of the other player of your group are 285 points.

\section{Appendix A.4. Sequence Corresponding to the CPR Game}

In each period, you must split your 10 tokens between your investment in activity A and your investment in your activity B. You are free to choose how you want to allocate your 10 tokens. For example, you can decide whether to allocate all your tokens in activity A or all your tokens in activity B. The earnings in activity A and activity B are exactly the same as in part 1, so you will use the same "Table of earnings" (Table A2 for the aggregated payoff and Table A1 for separated payoff treatments) as in part 1 (We write this sentence if CPR game is applied in sequence 2).

In practice, the computer will ask you to indicate the number of tokens you want to invest in activity A. The rest of your 10 tokens will automatically be invested in your activity B. The sum of these two investments is exactly equal to your 10 tokens for this period. As a result, you cannot transfer a part or all of your tokens from one period to another.

You and the other player make your decisions simultaneously. Once the investment decisions have been made, the computer calculates your total earnings, as well as the earnings of the other player for the current period. It will tell you how many tokens you have invested in each of the two activities and your total earnings in points. The same information about the other player will also be displayed on your screen. The next period can then begin. Before each new period, you will be informed about your total earnings from each of the previous periods. When the 10th period will be over, the computer will summarize the amount of your earnings for each of the 10 periods.

\section{Appendix A.5. Sequences Corresponding to the CPR with AM (The Threat of Nash Equilibrium)}

There are 10 periods in part 2 in which you will interact with the same person. You and the other player in your group must decide how much you will invest in activity $\mathrm{A}$. The earnings in activity A and activity B are exactly the same as in part 1, so you will use the same "Table of earnings" (Table A2 for the aggregated payoff and Table A1 for separated payoff treatments) as in part 1 (We write this sentence if CPR+AM is applied in sequence 2).

In part 2, each period consists of two stages: Stage 1 and Stage 2. Stage 1 corresponds to the investment decision: you and the other player will each have to decide how much to invest in activity A. Stage 1 corresponds exactly to the same investment decision as in part 1. Stage 2 is new. Once the two members of your group have chosen their amount to invest in activity $\mathrm{A}$, these decisions and their associated total earnings are published on the screens of all members (including yourself) and submitted for approval. If the two members of your group approve the proposed investment decisions, they will be applied and everyone will earn the corresponding earnings. If at least one player in your group disapprove, the computer will apply an identical investment level as explained in the following instructions.

In practice, in stage 1, the computer will ask you to indicate the amount of your investment in activity A. In stage 2, the computer will tell you how many tokens you proposed for both activities and how many tokens the other player proposed in the current period. It will also tell you your :

- total earning as well as the total earning of the other player. [under the treatments of aggregated payoff]

- $\quad$ earning of activity A and your earning of activity B as well as earnings of activity A and activity $B$ of the other player. [under the treatments of separated payoff]

Then, the computer will ask you whether you approve or reject the proposals from the other member of your group. You will click YES if you agree with the proposals, or NO if you disagree with the proposals. At the same time, the other player also has to approve or reject the proposals for the current period. 
Table A1. Table of earnings in activity A for $a=23, b=0.25$ and $p=5$.

\begin{tabular}{|c|c|c|c|c|c|c|c|c|c|c|c|c|}
\hline & & \multicolumn{11}{|c|}{ Mate } \\
\hline & & 0 & 1 & 2 & 3 & 4 & 5 & 6 & 7 & 8 & 9 & 10 \\
\hline \multirow{10}{*}{ self } & 0 & $0 ; \mathbf{0}$ & $0 ; 66.75$ & $0 ; \mathbf{1 2 9}$ & $0 ; \mathbf{1 8 6 . 7 5}$ & $0 ; \mathbf{2 4 0}$ & $0 ; \mathbf{2 8 8 . 7 5}$ & $0 ; 333$ & $0 ; 372.75$ & $0 ; 408$ & $0 ; 438.75$ & $0 ; 465$ \\
\hline & 1 & $66.75 ; 0$ & $64.5 ; 64.5$ & $62.25 ; 124.5$ & $60 ; \mathbf{1 8 0}$ & $57.75 ; 231$ & $55.5 ; 277.5$ & $53.25 ; 319.5$ & $51 ; 357$ & $48.75 ; 390$ & $46.5 ; \mathbf{4 1 8 . 5}$ & $44.25 ; 442.5$ \\
\hline & 2 & $129 ; 0$ & $124.5 ; 62.25$ & $120 ; \mathbf{1 2 0}$ & $115.5 ; \mathbf{1 7 3 . 2 5}$ & $111 ; 222$ & $106.5 ; 266.25$ & $102 ; 306$ & $97.5 ; 341.25$ & $93 ; 372$ & $88.5 ; 398.25$ & $84 ; 420$ \\
\hline & 3 & $186.75 ; 0$ & $180 ; 60$ & $173.25 ; \mathbf{1 1 5 . 5}$ & $166.5 ; \mathbf{1 6 6 . 5}$ & $159.75 ; \mathbf{2 1 3}$ & $153 ; 255$ & $146.25 ; 292.5$ & $139.5 ; 325.5$ & $132.75 ; 354$ & $126 ; 378$ & $119.25 ; 397.5$ \\
\hline & 4 & $240 ; 0$ & $231 ; 57.75$ & $222 ; 111$ & $213 ; 159.75$ & $204 ; 204$ & $195 ; 243.75$ & $186 ; 279$ & $177 ; 309.75$ & $168 ; 336$ & $159 ; 357.75$ & $150 ; 375$ \\
\hline & 6 & $333 ; 0$ & $319.5 ; \mathbf{5 3 . 2 5}$ & $306 ; 102$ & $292.5 ; \mathbf{1 4 6 . 2 5}$ & $279 ; \mathbf{1 8 6}$ & $265.5 ; 221.25$ & $252 ; 252$ & $238.5 ; \mathbf{2 7 8 . 2 5}$ & $225 ; 300$ & $211.5 ; 317.25$ & $198 ; 330$ \\
\hline & 7 & $372.75 ; 0$ & $357 ; \mathbf{5 1}$ & $341.25 ; 97.5$ & $325.5 ; \mathbf{1 3 9 . 5}$ & $309.75 ; \mathbf{1 7 7}$ & $294 ; 210$ & $278.25 ; 238.5$ & $262.5 ; 262.5$ & $246.75 ; 282$ & $231 ; 297$ & $215.25 ; \mathbf{3 0 7 . 5}$ \\
\hline & 8 & $408 ; 0$ & $390 ; 48.75$ & $372 ; 93$ & $354 ; 132.75$ & $336 ; \mathbf{1 6 8}$ & $318 ; \mathbf{1 9 8 . 7 5}$ & $300 ; 225$ & $282 ; 246.75$ & $264 ; 264$ & $246 ; 276.75$ & $228 ; 285$ \\
\hline & 9 & $438.75 ; 0$ & $418.5 ; 46.5$ & $398.25 ; 88.5$ & $378 ; \mathbf{1 2 6}$ & $357.75 ; 159$ & $337.5 ; \mathbf{1 8 7 . 5}$ & $317.25 ; 211.5$ & $297 ; 231$ & $276.75 ; 246$ & $256.5 ; 256.5$ & $236.25 ; \mathbf{2 6 2 . 5}$ \\
\hline & 10 & $465 ; 0$ & $442.5 ; 44.25$ & $420 ; 84$ & $397.5 ; \mathbf{1 1 9 . 2 5}$ & $375 ; \mathbf{1 5 0}$ & $352.5 ; \mathbf{1 7 6 . 2 5}$ & $330 ; 198$ & $307.5 ; 215.25$ & $285 ; 228$ & $262.5 ; 236.25$ & $240 ; 240$ \\
\hline
\end{tabular}

Table A2. Table of total earnings for $a=23, b=0.25$ and $p=5$.

\begin{tabular}{|c|c|c|c|c|c|c|c|c|c|c|c|c|}
\hline & & \multicolumn{11}{|c|}{ Mate } \\
\hline & & 0 & 1 & 2 & 3 & 4 & 5 & 6 & 7 & 8 & 9 & 10 \\
\hline \multirow{10}{*}{ self } & 0 & $150 ; \mathbf{1 5 0}$ & $150 ; 201.75$ & $150 ; 249$ & $150 ; 291.75$ & $150 ; 330$ & $150 ; 363.75$ & $150 ; 393$ & $150 ; \mathbf{4 1 7 . 7 5}$ & $150 ; 438$ & $150 ; 453.75$ & $150 ; 465$ \\
\hline & 1 & $201.75 ; \mathbf{1 5 0}$ & $199.5 ; \mathbf{1 9 9 . 5}$ & $197.25 ; \mathbf{2 4 4 . 5}$ & $195 ; 285$ & $192.75 ; \mathbf{3 2 1}$ & $190.5 ; 352.5$ & $188.25 ; 379.5$ & $186 ; 402$ & $183.75 ; 420$ & $181.5 ; 433.5$ & $179.25 ; \mathbf{4 4 2 . 5}$ \\
\hline & 2 & $249 ; \mathbf{1 5 0}$ & $244.5 ; \mathbf{1 9 7 . 2 5}$ & $240 ; 240$ & $235.5 ; 278.25$ & $231 ; 312$ & $226.5 ; 341.25$ & $222 ; 366$ & $217.5 ; 386.25$ & $213 ; 402$ & $208.5 ; 413.25$ & $204 ; 420$ \\
\hline & 3 & $291.75 ; \mathbf{1 5 0}$ & $285 ; 195$ & $278.25 ; 235.5$ & $271.5 ; 271.5$ & $264.75 ; 303$ & $258 ; 330$ & $251.25 ; 352.5$ & $244.5 ; 370.5$ & $237.75 ; 384$ & $231 ; 393$ & $224.25 ; 397.5$ \\
\hline & 4 & $330 ; 150$ & $321 ; \mathbf{1 9 2 . 7 5}$ & $312 ; 231$ & $303 ; 264.75$ & $294 ; 294$ & $285 ; 318.75$ & $276 ; 339$ & $267 ; 354.75$ & $258 ; 366$ & $249 ; 372.75$ & $240 ; 375$ \\
\hline & 5 & $363.75 ; \mathbf{1 5 0}$ & $352.5 ; \mathbf{1 9 0 . 5 0}$ & $341.25 ; 226.5$ & $330 ; 258$ & $318.75 ; 285$ & $307.5 ; 307.5$ & $296.25 ; 325.5$ & $285 ; 339$ & $273.75 ; 348$ & $262.5 ; 352.5$ & $251.25 ; 352.5$ \\
\hline & 7 & $417.75 ; \mathbf{1 5 0}$ & $402 ; \mathbf{1 8 6}$ & $386.25 ; 217.5$ & $370.5 ; 244.5$ & $354.75 ; 267$ & $339 ; 285$ & $323.25 ; 298.5$ & $307.5 ; 307.5$ & $291.75 ; 312$ & $276 ; 312$ & $260.25 ; 307.5$ \\
\hline & 8 & $438 ; \mathbf{1 5 0}$ & $420 ; \mathbf{1 8 3 . 7 5}$ & $402 ; 213$ & $384 ; 237.75$ & $366 ; 258$ & $348 ; 273.75$ & $330 ; 285$ & $312 ; \mathbf{2 9 1 . 7 5}$ & $294 ; 294$ & $276 ; 291.75$ & $258 ; 285$ \\
\hline & 9 & $453.75 ; \mathbf{1 5 0}$ & $433.5 ; \mathbf{1 8 1 . 5}$ & $413.25 ; \mathbf{2 0 8 . 5}$ & $393 ; 231$ & $372.75 ; 249$ & $352.5 ; 262.5$ & $332.25 ; 271.5$ & $312 ; 276$ & $291.75 ; 276$ & $271.5 ; 271.5$ & $251.25 ; \mathbf{2 6 2 . 5}$ \\
\hline & 10 & $465 ; \mathbf{1 5 0}$ & $442.5 ; \mathbf{1 7 9 . 2 5}$ & $420 ; 204$ & $397.5 ; 224.25$ & $375 ; \mathbf{2 4 0}$ & $352.5 ; 251.25$ & $330 ; 258$ & $307.5 ; \mathbf{2 6 0 . 2 5}$ & $285 ; 258$ & $262.5 ; 251.25$ & $240 ; 240$ \\
\hline
\end{tabular}


As aforementioned, if they approve, the computer implements the proposals. Otherwise, it imposes a uniform level of investment in activity A, always 8 tokens (This value corresponds to the predicted symmetric Nash equilibrium of the CPR game) and the rest of the 10 tokens is invested in activity B. Then the computer will display the investments (tokens in activities A and B respectively) and the total earnings.

At the end of stage 2, the computer displays the final total earnings of each group member for that period. The next period can then start. Before each new period you will know your earnings for each of the previous periods. When the 10th period is over, the computer will summarize the amount of your total earnings for each of the 10 periods.

The exchange rate is 1 euro for 15 points. One of the 20 periods will be randomly chosen to be paid out for real.

\section{Appendix A.6. Sequence 2 of Control Treatment}

As in part 1, there are 10 periods in part 2 in which you will interact with the same persons as in part 1 . You and the other player in your group must decide how much you will invest in activity A. The earnings in activity A and activity B are exactly the same as in part 1, so you will use the same "Table of total earnings" as in part 1.

You and the other player(s) make your investment decisions simultaneously. Once the investment decisions have been made, the computer calculates your total earnings, as well as the earnings of the other player in your group for the current period. It will show you how many tokens you invested in each of the two activities and your total earnings in points. The same information about the other player will also be displayed on your screen. The next period can then begin. Before each new period, you know your total earnings from each of the previous periods. When the 10th period is over, the computer will summarize the amount of your winnings for each of the 10 periods

The exchange rate is 1 euro for 15 points. One of the 20 periods is randomly drawn to be remunerated.

\section{References}

1. Kollock, P. Social dilemmas: The anatomy of cooperation. Annu. Rev. Sociol. 1998, 24, 183-214. [CrossRef]

2. Balliet, D. Communication and cooperation in social dilemmas: A meta-analytic review. J. Confl. Resolut. 2010, 54, 39-57. [CrossRef]

3. Foot, P. The Problem of Abortion and the Doctrine of Double Effect. Oxf. Rev. 1967, 5, 5-15.

4. Hardin, G. The tragedy of the commons. Science 1968, 162, 1243-1248. [CrossRef]

5. Ostrom, E. Governing the Commons: The Evolution of Institutions for Collective Action; Cambridge University Press: Cambridge, UK, 1990.

6. Adar, E.; Huberman, B.A. Free Riding on Gnutella. First Monday 2000, 5. [CrossRef]

7. Russell, E.S. The Overfishing Problem; CUP Archive: Cambridge, UK, 1942.

8. Gordon, H.S. The economic theory of a common-property resource: The fishery. In Classic Papers in Natural Resource Economics; Springer: Berlin/Heidelberg, Germany, 1954; pp. 178-203.

9. Koslow, J.A.; Boehlert, G.W.; Gordon, J.D.M.; Haedrich, R.L.; Lorance, P.; Parin, N. Continental slope and deep-sea sheries: Implications for a fragile ecosystem. ICES J. Mar. Sci. 2000, 57, 548-557. [CrossRef]

10. Gordon, J.D. Deep-water sheries at the Atlantic Frontier. Cont. Shelf Res. 2001, 21, 987-1003. [CrossRef]

11. Walker, J.M.; Gardner, R.; Ostrom, E. Rent dissipation in a limited-access common-pool resource: Experimental evidence. J. Environ. Econ. Manag. 1990, 19, 203-211. [CrossRef]

12. Keser, C.; Gardner, R. Strategic behavior of experienced subjects in a common pool resource game. Int. J. Game Theory 1999, 28, 241-252. [CrossRef]

13. Cardenas, J.C. Norms from outside and from inside: An experimental analysis on the governance of local ecosystems. For. Policy Econ. 2004, 6, 229-241. [CrossRef]

14. Ostrom, E. The value-added of laboratory experiments for the study of institutions and common-pool resources. J. Econ. Behav. Organ. 2006, 61, 149-163. [CrossRef]

15. Cárdenas, J.; Mantilla, C.; Sethi, R. Stable sampling equilibrium in common pool resource games. Games 2015, 6, 299-317. [CrossRef]

16. Masuda, T.; Okano, Y.; Saijo, T. The minimum approval mechanism implements the efficient public good allocation theoretically and experimentally. Games Econ. Behav. 2014, 83, 73-85. [CrossRef] 
17. Yao, K.S.W.; Lavaine, E.; Willinger, M. Does the approval mechanism induce the effcient extraction in Common Pool Resource games? Soc. Choice Welf. 2021. [CrossRef]

18. Nash, J. Two-person cooperative games. Econometrica 1953, 21, 128-140. [CrossRef]

19. Lindahl, T.; Crépin, A.S.; Schill, C. Potential disasters can turn the tragedy into success. Environ. Resour. Econ. 2016, 65, 657-676. [CrossRef]

20. Saijo, T.; Feng, J.; Kobayashi, Y. Common-pool resources are intrinsically unstable. Int. J. Commons 2017, 11, 597-620. [CrossRef]

21. Saijo, T.; Masuda, T.; Yamakawa, T. Approval mechanism to solve prisoner's dilemma: Comparison with Varian's compensation mechanism. Soc. Choice Welf. 2018, 51, 65-77. [CrossRef]

22. Gneezy, U.; Rustichini, A. A fine is a price. J. Leg. Stud. 2000, 29, 1-17. [CrossRef]

23. Fischbacher, U. z-Tree: Zurich toolbox for ready-made economic experiments. Exp. Econ. 2007, 10, 171-178. [CrossRef]

24. Varian, H.R. A solution to the problem of externalities when agents are well-informed. Am. Econ. Rev. 1994, 84, 1278-1293.

25. Falkinger, J. Efficient private provision of public goods by rewarding deviations from average. J. Public Econ. 1996, 62, 413-422. [CrossRef]

26. Gächter, S.; Kölle, F.; Quercia, S. Reciprocity and the tragedies of maintaining and providing the commons. Nat. Hum. Behav. 2017, 1, 650-656. [CrossRef] [PubMed] 